\title{
Sentido qualitativo de diferença, autorreferência e o caráter diáfano da consciência em Sérgio L. de C. Fernandes
}

\author{
Qualitative meaning of difference, \\ self-reference and the diaphanous character of \\ consciousness in Sérgio L. de C. Fernandes
}

\begin{abstract}
Resumo
O presente artigo é uma homenagem ao professor Sérgio Luiz de Castilho Fernandes. Encontra-se dividido em três partes. A primeira delas apresenta a visão do autor sobre os conceitos de "qualidade" e "quantidade". Contrapõe o sentido numérico ao sentido qualitativo de diferença, através do exame do conceito de "duração". Examina, em seguida, a ideia de que haja um "eu" que permaneça idêntico a si mesmo ao longo do tempo. Por fim, o artigo expõe a teoria de Sérgio Fernandes sobre o "caráter diáfano" da consciência através do que o autor denomina de "Mito do Jogo de Luz".
\end{abstract}

Palavras-chaves: Qualidade; diferença; duração; autorreferência; identidade pessoal; consciência.

\begin{abstract}
The present paper is a tribute to Professor Sérgio Luiz de Castilho Fernandes. It is divided into three parts. The first one presents the author's view on the concepts of "quality" and "quantity". It contrasts the numerical sense with the qualitative sense of difference by examining the concept of "duration". He then examines the
\end{abstract}

\footnotetext{
* Professor do Departamento de Filosofia e do Programa de Pós-Graduação em Filosofia da UFF. E-mail: cdctourinho@yahoo.com.br.
}

Recebido em: 13/02/2019. Aceito em: 14/07/2019. 
idea that there is an "I" that remains identical to itself over time. Finally, the article exposes Sérgio Fernandes' theory of the "diaphanous character" of consciousness through what the author calls "Myth of the Game of Light".

Keywords: Quality; difference; duration; self-reference; personal identity; consciousness.

\section{Introdução}

O presente artigo é uma homenagem ao professor Sérgio Luiz de Castilho Fernandes. Dividido em três partes, o artigo concentra-se, inicialmente, em torno das considerações do autor sobre os conceitos de "qualidade" e "quantidade" no artigo publicado em 1996, para a Revista Mente Social da Universidade Gama Filho. Em seguida, ainda na primeira parte, contrasta, através do exame do conceito de "duração", o sentido "numérico" de diferença com o sentido "qualitativo" do que significa "distinguir o mesmo do outro". A segunda parte examina a ideia de que haja um "eu" que permaneça idêntico a si mesmo ao longo do tempo. Apoiando-se em Filosofia e Consciência (1995), o artigo aborda a crítica de Sérgio Fernandes à ideia de "autorreferência" na constituição da identidade pessoal. A última parte dedica-se às considerações do autor sobre o debate na Filosofia da Mente contemporânea em torno da possibilidade de uma "ciência da mente". Por fim, o artigo apresenta a teoria de Sérgio Fernandes sobre o "caráter diáfano" da consciência através do que o autor denomina de "Mito do Jogo de Luz". Passemos, então, a uma exposição mais detalhada de cada uma das partes mencionadas.

\section{Qualidade, Diferença e Duração}

Em "Qualidade e Quantidade em Pesquisa Psicológica", artigo escrito em 1996 para a Revista Mente Social da Universidade Gama Filho (UGF), o professor Sérgio L. de C. Fernandes chama-nos a atenção para as suas considerações sobre os conceitos de "qualidade" e de "quantidade", subentendendo, na elucidação de tais conceitos, um sentido "numérico" do que significa distinguir duas coisas quaisquer. $\mathrm{O}$ autor afirma-nos que tudo o que podemos tratar em termos numéricos (ou "quantitativos") supõe uma "qualidade" que, por sua vez, é justamente o que nos permite identificar, 
classificar e, por conseguinte, contar indivíduos que se distinguem uns dos outros numericamente. Remetendo-nos para a Teoria dos Conjuntos, Sérgio Fernandes considera a qualidade como uma "propriedade extrínseca" por intermédio da qual definimos, operacionalmente, um dado conjunto de coisas, subsumindo (se a considerarmos como um "conceito", para falar em termos kantianos) os indivíduos que, compartilhando a mesma propriedade, fazem parte do referido conjunto. Neste sentido, só podemos formar um conjunto a partir de uma qualidade: o conjunto dos $\mathrm{x}$, tal que x tem a propriedade P. Simbolizando a propriedade por "P" e deixando vago o lugar da coisa, marcando-o com a variável " $\mathrm{x}$ ", diríamos: "P(x)". As coisas que satisfazem esta função encontram-se no domínio de "P". O autor afirma-nos, então, no referido artigo, que a Matemática começa pressupondo a qualidade e somente se desenvolve pressupondo a "repetição da qualidade"1. E é justamente aí que surge, para Sérgio Fernandes, como que por um fiat, a ideia de "quantidade", quando fazemos com que a qualidade, que não é ela mesma uma "coisa contável" (por ser justamente o que nos permite contar), se repita. Neste sentido, o autor alerta-nos para o que significa, propriamente, "quantificar algo": não se trata de contar indivíduos, mas sim, o número de vezes em que uma dada qualidade se repete em um elenco de indivíduos pertencentes a um dado conjunto. Supondo um fundo homogêneo (indistinto) do qual os indivíduos numericamente se destacam, reduzindo-os a uma função comum, passamos a contá-los na medida em que os mesmos compartilham a referida função. Contamos, então, o número de vezes em que tal função se repete, de modo que os indivíduos que "caem" sob uma mesma qualidade se distinguem tão somente in numero. As qualidades não são contáveis, pois são, justamente, o que nos permite "contar", e não o contrário. Ainda assim, mesmo que não sejam contáveis, lembra-nos o autor, estranhamente, "se repetem"!?

Se os indivíduos pertencentes a um dado conjunto se distinguem tão somente em termos numéricos, do ponto de vista qualitativo, é como se eles "fossem um só". Sendo assim, o autor opta por preservar, sobretudo, quando se trata daquilo que considera "útil" em ciência, um sentido meramente numérico de diferença entre os indivíduos que, por sua vez, como vimos acima, somente podem ser contados na medida em que são, por meio de uma

1 Cf. Fernandes, S. L. de C. "Qualidade e Quantidade em Pesquisa Psicológica". In: Psicologia E Mente Social (UGF), 1996, p. 206.

2 Cf. Idem. 
qualidade, identificados, classificados enquanto membros de um conjunto. Afinal, como poderia o que não tem qualidade e, portanto, o que não pode ser identificado, percebido, pensado, etc, repetir-se?

Ao considerar, apoiando-se na Teoria dos Conjuntos, a qualidade em termos de "propriedade extrínseca", Sérgio Fernandes restringe, portanto, o conceito de diferença a um sentido meramente numérico. $\quad \mathrm{P}$ o r outro lado, se a quantidade é, em última análise, a "repetição de uma qualidade", somente poderíamos "distinguir" uma coisa de outra na medida em que atribuíssemos a essa coisa uma qualidade. Mas, alerta-nos o autor, se uma qualidade - enquanto o que me permite identificar, classificar e, portanto "distinguir" - fosse uma qualidade diferente a cada vez que aparecesse, então, ela não se repetiria e não serviria para contar. Neste sentido, para que possa exercer este "papel", a qualidade deve ser considerada em termos "relacionais", enquanto "qualidade de alguma coisa". Do contrário, teríamos que pensar a qualidade em termos "exclusivos" ou "intrínsecos". Mas, isso equivaleria, segundo Sérgio Fernandes, a considerá-la como "indivíduo" (único e irrepetível). E se é nisto que consiste a diferença, então, para Sérgio Fernandes, tal diferença seria inútil em ciência. Como diz o autor: "Ela representa apenas a ideia de que não há duas coisas iguais e ponto! Não haveria como dar conteúdo a esta ideia vazia"”.

Mas, devemos notar outra via - não explorada por Sérgio Fernandes no artigo de 1996 - por meio da qual deparamo-nos com um duplo sentido do que significa "distinguir o mesmo do outro". Tais sentidos (igualmente, denominados de "numérico" e "qualitativo") encontram-se, respectivamente, alinhados com o "espaço" e o "tempo". Se o primeiro sentido encontra-se relacionado ao espaço (a um fundo homogêneo e indistinto) no qual se localizam todos os elementos que distinguimos numericamente, o segundo encontrar-se-ia relacionado ao tempo. Trata-se, aqui, do tempo concebido não como uma grandeza numérica (o tempo objetivo da ciência, o tempo do relógio, medido pela posição do sol, etc.), mas como "vivência consciente de duração", na qual os momentos vividos temporalmente sucedem-se, continuamente, uns em relação aos outros e, na medida em que passam, juntam-se aos anteriores, deixando um "rastro" para os momentos seguintes, despertando, com isso, uma nova expectativa em relação a um futuro iminente. A dimensão temporal (ou "genética") permite-nos, com isso, pensar a distinção

3 Cf. Fernandes, S. L. de C. "Qualidade e Quantidade em Pesquisa Psicológica". In: Psicologia \& Mente Social (UGF), 1996, p. 209. 
entre os momentos vividos na duração, sem que tenhamos, com isso, que separá-los como "partes" (numericamente distintas umas das outras). Dentre os autores de ascendência judia para os quais o tempo seria, nas origens da Filosofia Contemporânea, pensado como "vivência de duração", é possível identificar, em particular, dois nomes: Edmund Husserl e Henri Bergson. Mas, se o primeiro converge suas considerações para uma abordagem genética da intencionalidade (cujo propósito consiste em investigar "conexões" entre vividos intencionais), o segundo apresenta-nos, ao conceber a consciência como "memória", um novo sentido para o verbo "distinguir", para além de uma diferenciação meramente numérica.

No famoso capítulo dois de sua tese de doutoramento de 1889, intitulada Ensaio sobre os dados imediatos da consciência, Bergson afirma-nos certa dualidade que, ao se abrir, coloca, de um lado, os "corpos", e de outro, o "espírito" (a vida interior da consciência), alinhando-os, correlativamente, a duas multiplicidades, cada uma das quais contendo um sentido próprio do que significa "distinguir" os elementos que as compõem. De um lado, uma multiplicidade numérica (ou quantitativa), própria dos corpos que se justapõem no espaço ("homogêneo" ou "indistinto") e que se distinguem numericamente por intervalos vazios, mantendo-se, nas palavras do autor, em uma relação uns com os outros de "exterioridade recíproca sem sucessão" 4 . Por outro lado, uma multiplicidade qualitativa, própria da vida interior da consciência, na qual os momentos vividos se prolongariam continuamente, desenrolando-se, sucessivamente, uns em relação aos outros, por uma espécie de "penetração mútua"5. Se na multiplicidade numérica (ou quantitativa), corpos se distinguem, numericamente, uns dos outros na medida em que ocupam lugares distintos no espaço, na multiplicidade qualitativa, os momentos conscientes distinguem-se uns dos outros, ainda que não estejam separados, pois, na medida em que se sucedem continuamente em uma vivência de duração, o momento anterior dá lugar ao momento seguinte, de modo que os "ecos" do primeiro - que passou e, ao passar, se juntou aos anteriores - ainda "ressoam", colocando-nos, no momento seguinte, frente a uma nova expectativa em relação aos momentos que estão por vir. Tais relações com o passado imediato e o futuro iminente tornam, qualitativamente, "únicos" cada momento consciente em uma vivência de duração. O

4 Cf. Bergson, H. Essai sur les données immédiates de la conscience. In: Oeuvres. Paris: PUF, ([1889] 1959), p. 73.

5 Cf. Ibidem, p. 88. 
novo sentido de distinguir um momento de outro mantém relação não com o espaço, mas com o tempo. Note-se ainda que, na teoria bergsoniana da duração, a "distinção qualitativa" torna-se, diferentemente do que notamos no artigo de 1996 do professor Sérgio Fernandes, inerente à vivência temporal de duração. Mas, se em tal teoria, as considerações convergem para o tema da duração, para o referido professor, o tema em questão, sobretudo, o que ele supõe, contém uma "ilusão irresistível".

\section{O problema da autorreferência na identidade pessoal}

Ao contrário do que poderia parecer, "onde há duração, há mudança". Novamente, Bergson - o "filósofo da duração" - trata dessa questão, contrariando o modo habitual de pensar, afirmando-nos que o que torna, propriamente, possível a duração é, justamente, a mudança ou a passagem dos momentos da vida consciente, pois, só podemos atribuir duração a alguma coisa (a um organismo qualquer) na medida em que tais momentos passam sucessivamente, pois, passando, conservam-se nos momentos seguintes, pela capacidade da memória de preservar "o antes no depois". Para Bergson, toda duração (por menor que seja) supõe memória, isto é, a capacidade de conservar e acumular o passado, contraindo-o no momento seguinte, preservando, enfim, o que não é mais no que é. E é por isso que, para Bergson, toda duração implica consciência. A memória - que é justamente o que toda duração supõe - pode ser ínfima (reduzida a "um antes e um depois"), mas, "a memória existe, ou então não existe consciência" . Porém, se Bergson contraria o modo habitual de pensar, ao afirmar que algo somente "dura" na medida em que "passa", não contraria, contudo, o que tal modo de pensar supõe: o "eu" que dura ao longo do tempo. Segundo Bergson, a vivência de duração que melhor conhecemos é, justamente, a do nosso próprio "eu". Trata-se, segundo o autor, de uma realidade que apreendemos, seguramente, por intuição, "de dentro": "É nossa própria pessoa em seu fluir através do tempo. É nosso eu que dura"7. Podemos não simpatizar com coisa alguma, mas, simpatizamo-nos,

6 Cf. Bergson, H. "La Conscience et la Vie". L'Énergie Spirituelle. In: Oeuvres. Paris: PUF, ([1911] 1959), p. 818.

7 Cf. Bergson, H. "Introduction à la Métaphysique". La Pensée et le Mouvant. In: Oeuvres. Paris: PUF, ([1903] 1959), p. 1396. 
seguramente, "conosco mesmos" 8 . Em tal realidade que apreendemos "de dentro" ( $d u$ dedans), tratar-se-ia de uma "evidência incorrigível", a qual tenho acesso privilegiado, do ponto de vista da primeira pessoa. Mas, o que Sérgio Fernandes teria a nos dizer sobre tal "realidade interior" que, supostamente, nos é revelada em uma "evidência incorrigível"?

A resposta a essa questão encontra-se em uma publicação de 1995, no segundo livro de Sérgio Fernandes, intitulado Filosofia e Consciência (livro cujas teses foram intensamente debatidas nos famosos seminários de Teoria do Conhecimento, coordenados pelo próprio professor, como disciplina do Programa de Pós-Graduação em Filosofia da PUC-Rio). Na contramão do bergsonismo, para o professor Sérgio Fernandes, torna-se pouco clara a ideia de que o que chamamos de "eu" possa manter-se "idêntico a si mesmo", ao longo do tempo. Afinal, toda duração é duração "em relação aquilo" que dura: no caso, a duração em questão é atribuída ao "eu" (algo que, supostamente, persiste continuamente idêntico no curso de nossa existência). O autor afirma-nos, em Filosofia e Consciência, que tal ideia consiste em uma "ilusão". Comumente, nos diz o professor Sérgio, pensamos que uma identificação consiste em um ato intencional, dirigido "para fora" - "o policial nos interpe-

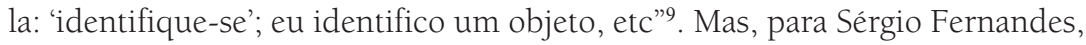
deve haver uma identificação primária, dita "inconsciente", por meio da qual se torna necessário que, ao dizer "eu", não conheça quem o diz. Caso seja necessário dizer "eu" sem saber quem sou, então, isto não será necessário apenas nos casos nos quais identifico coisas em geral (como por exemplo, quando digo: "Eu vejo uma estrela"), mas também quando identifico o "eu" como o "objeto" com o qual me identifico. Para o autor, este voltar de fora para dentro a identificação é ilusório, pois me põe "para fora" como objeto de identificação. Notamos aí, segundo o autor, um paradoxo: "se for necessário que eu não conheça quem sou para que eu conheça o que quer que seja, para que eu conheça a 'mim mesmo' será necessário que eu não conheça a mim mesmo"10. Em outros termos, se for necessário que eu esteja inconsciente de mim mesmo para poder estar consciente de "outra coisa", então, no caso de essa outra coisa ser "eu mesmo", só poderei estar consciente dela, se eu estiver inconsciente de mim mesmo. Todo problema parece residir, então, para

8 Cf. Idem.

9 Cf. Fernandes, S. L. de C. Filosofia e Consciência. Uma investigação ontológica da Consciência. Rio de Janeiro: Areté Editora, 1995, p. 160.

10 Cf. Idem. 
o autor, na relação de identidade - que, como em toda relação, supõe dois relata - do "eu" (inconsciente) com a "pessoa" com a qual se identifica. Se é necessário que só possamos dizer "eu" na inconsciência, quando "introspectamos", temos diante de nós um "objeto". E é contingente que esse objeto seja a pessoa com quem me identifico, denominando-a de "eu mesmo". Daí o autor dizer: "Toda instrospecção é uma extrospecção"11. Em suma, uma identificação primária, inconsciente, pela qual digo "eu", sem saber quem o diz, é o que me permite identificar, secundariamente e, portanto, "lá fora", a persona (objeto) que constituo, intencionalmente, como "eu". Mas, se para Sérgio Fernandes, tais identificações (primária e secundária) escondem a "distinção" entre os pólos desta relação, para certos autores, anteriores a Bergson, o princípio segundo o qual quando pensamos reflexivamente sobre algo o fazemos enquanto uma "mesma pessoa" tratar-se-ia de uma evidência incorrigível.

A propósito do tema em questão, sabemos, através da História da Filosofia Moderna, que o chamado "princípio de identidade pessoal" foi aceito inadvertidamente por autores seiscentistas, na condição de uma certeza que "dispensaria provas". No caso de John Locke, para quem podemos afirmar, em sentido psicológico e moral, uma teoria da "pessoa", especificamente, no capítulo XXVII do Livro II de Ensaio sobre o Entendimento Humano (1690), a identidade pessoal encontrar-se-ia, do ponto de vista psicológico, diretamente ligada à capacidade retrospectiva da consciência de ligar os acontecimentos passados (conservados pela memória) com os acontecimentos presentes, identificando-os enquanto eventos vividos pela "mesma pessoa"12. Mas, se em Locke a evidência de que somos a "mesma pessoa" quando refletimos conscientemente sobre algo (revivendo, no presente, um acontecimento passado) torna-se uma certeza incorrigível, para David Hume, ao contrário, o sentimento de que somos os "mesmos" (da nossa "continuidade" na existência) não é senão uma "ficção", forjada pela operação da faculdade da imaginação sobre os objetos. Como ele próprio nos diz, no Livro I do seu Tratado da Natureza Humana (1739/1740), o eu não é senão uma "coleção" de diferentes percepções (collection of different perceptions) $)^{13}$. Até então, inquestionável, a evidência de que somos os "mesmos" a pensar e refletir conscientemente

11 Cf. Ibidem, p. 161.

12 Cf. Locke, J. An Essay Concerning Human Understanding. New York: Dover Publications, INC, ([1690]1959), Book II, cap. XXVII, \& 11 (Personal Identity); pp. 448/449.

13 Cf. Hume, D. A Treatise of Human Nature. Oxford, New York: Clarendon Press, 2007, (Book 1, Part IV, Sect 6), p. 165. 
sobre algo, termina, no Tratado de Hume, por se esvair em um "múltiplo de percepções". Não posso procurar por "mim mesmo" (myself) sem que, em qualquer tempo, seja remetido para alguma percepção ou outra (de calor ou frio, luz ou escuridão, amor ou ódio, etc), jamais encontrando aquilo que sinto continuamente como "eu mesmo"14. Daí o professor Sérgio Fernandes dizer, em Filosofia e Consciência, em uma aparente referência à crítica humeana ao princípio de identidade pessoal: "Mas há, aqui mesmo onde o Sol se põe, no Ocidente...quem introspecte e não encontre, nem um eu a ser observado, nem, portanto, suas atividades a experimentar, pensar, perceber. Há quem só encontre experiências..."15. Vejamos, então, mais claramente, porque o ilustre professor encontra-se, neste ponto, mais próximo de Hume do que de Locke.

Se para Locke a identidade pessoal encontra-se diretamente relacionada à capacidade retrospectiva da consciência, é preciso esclarecer, contudo, que tal capacidade supõe o próprio movimento reflexivo consciente, sem o qual jamais teríamos, segundo o autor, do ponto de vista psicológico, consciência de pensarmos e refletirmos sobre algo enquanto uma "mesma pessoa". Eis um ponto que, aliás, aproxima Locke de Descartes. Sabemos que, a despeito das diferenças entre tais autores, Locke é, sob muitos aspectos, um "cartesiano", ao aceitar, por exemplo, que "toda ideia é ideia de algo", "todo pensamento é um pensamento consciente", e assim por diante. Dentre estes aspectos, destacamos, especificamente, a aceitação do princípio segundo o qual quando penso e reflito conscientemente sobre algo (ou mesmo, sobre o que sou), o faço enquanto um "mesmo eu"16 (uma "mesma pessoa", diria Locke). Eis, então, o ponto sobre o qual Sérgio Fernandes concentra suas críticas: o movimento reflexivo da "consciência de si", relacionado por Locke à identidade pessoal. Deparamo-nos, então, com o que o professor Sérgio Fernandes designa como um "erro", atribuído a Descartes, mas, encontrado, igualmente, na teoria da pessoa de Locke.

O erro em questão estaria, para o referido professor, relacionado ao caráter paradoxal do princípio segundo o qual temos uma evidência incorrigível de que somos a "mesma pessoa" a pensar e refletir conscientemente sobre algo.

14 Cf. Idem.

15 Cf. Fernandes, S. L. de C. Filosofia e Consciência. Uma investigação ontológica da Consciência. Rio de Janeiro: Areté Editora, 1995, p. 142

16 No § 9 da Meditação Segunda, Descartes supõe a identidade do "eu", nas seguintes passagens: "Não sou eu próprio esse mesmo que duvida de quase tudo...?"; "Enfim, sou o mesmo que sente, isto é, que recebe e conhece as coisas como que pelos orgãos dos sentidos...". Cf. Descartes, R. Les Méditations Métaphysiques. Paris: Bordas, 1987, pp. 22-23. 
Afinal, se a objetividade do mundo requer um distanciamento mínimo entre um "ponto cego" de onde parte a referência objetiva e o que é objetivado, não podendo haver jamais um colapso entre tais pólos, a ideia de que haja uma evidência incorrigível a partir de um suposto movimento de autorreferência da "consciência de si" torna-se, segundo o autor, uma contradictio in terminis. Sérgio Fernandes apresenta-nos, então, a fórmula: "conheço x não sou x"17. Caso a adotemos, aplicando-a à "consciência de si", deparar-nos-emos, inevitavelmente, com tal contradição: não posso objetivar a "mim mesmo" (portanto, colocando esse "mim mesmo" no lugar de "x") sem que deixe de ser eu mesmo para me tornar um "outro", de modo que, para o autor, jamais poderíamos ser aquilo que pensamos. Com frequência, em suas aulas, relacionava tal impossibilidade ao mito de "Uroboros" (a serpente que morde o próprio rabo, mas que jamais pode alcançar a sua própria cabeça). Se o princípio de identidade pessoal encontra-se comprometido com a chamada "consciência de si", uma vez revelado o caráter contraditório de tal consciência reflexiva, o próprio princípio encontrar-se-ia em questão. Mas, se Sérgio Fernandes insiste, demasiadamente, no "curto-circuito urobórico" da ideia de "consciência de si", é na medida em que tal ideia traz consigo uma reflexividade da qual resulta um "colapso" na consciência, gerando, com isso, certa ambigüidade. Mais precisamente, toda reflexão supõe um "refletor" que, no caso da "consciência de si", comportaria um duplo sentido: "ativo" e "passivo". Como o próprio Sérgio gostava de exemplificar em seus seminários: dizemos, habitualmente, que um projetor "reflete luz" e, ao mesmo tempo, dizemos que a tela "reflete luz". No primeiro caso, evocamos um sentido "ativo" de reflexão, ao passo que, no segundo, um sentido "passivo". Segundo ele, a reflexividade da "consciência de si" colapsa tais sentidos, ao considerar, num só tempo, a consciência como "projetor" e como "tela". Tal colapso justifica o empenho de Sérgio Fernandes em pensar o conceito filosófico de "consciência", dissociando-o da ideia de "reflexividade". O autor dispõe-se a pensar a consciência em outros termos. Vejamos.

\section{Ciência da mente e diafaneidade da consciência no "Jogo de Luz".}

No que concerne ao cenário contemporâneo da Filosofia da Mente, Sérgio Fernandes jamais deixou de manifestar a sua oposição ao elenco de autores - nos quais incluímos Thomas Nagel (1974), Frank Jackson (1986), dentre

17 Cf. Fernandes, S. L. de C. Filosofia e Consciência. Uma investigação ontológica da Consciência. Rio de Janeiro: Areté Editora, 1995, p. 171. 
outros - para os quais a irredutibilidade dos qualia (das propriedades ditas "subjetivas" da experiência consciente, reveladas, exclusivamente, do ponto de vista da primeira pessoa, tais como, "emoções", "crenças", "desejos", etc.) consistiria no principal obstáculo para se levar adiante o projeto de uma ciência da mente ${ }^{18}$. Para tais autores, nós jamais poderíamos saber "como é ser aquele organismo consciente do ponto de vista dele". Contradizendo-os, Sérgio Fernandes mostrava-se categórico, ao afirmar: "Tampouco ele!". É quase como se o "Erro de Descartes" atuasse, nos termos do autor, como um "verdadeiro entorpecente" na mente de tais autores em pleno século $\mathrm{XX}^{19}$.

Sérgio Fernandes não via qualquer problema no projeto de uma "ciência da mente", ainda que considerasse inaceitável em ciência a posição de alguns materialistas, tais como U. T. Place (1956), J. J. C. Smart (1959), Paul Churchland (1984), dentre outros, para os quais os estados mentais nada mais seriam que estados e processos físicos cerebrais, de modo que para cada tipo de estado mental teríamos um tipo de estado cerebral ${ }^{20}$. Como insistia em dizer, na atividade científica, deparamo-nos com uma "redução epistêmica", cientificamente aceitável, mas, jamais como uma redução ontológica do tipo "x nada mais é que y", tal como postulam os chamados "materialistas redutivos". Afinal, em ciência, o que fala mais alto é o poder explicativo e preditivo das teorias. E explicar uma coisa qualquer não é senão tomar o explicandum em termos do explicans. Trata-se sempre de uma tomada "parcial" daquilo que se quer explicar e, portanto, como costumava dizer Sérgio Fernandes, de uma "reação tipicamente simbólica" (uma vez que colocamos uma coisa no lugar de outra). O professor alertava-nos, em seus seminários: "Explicar não é livrar-se dos objetos!" Não explicamos, portanto, coisa alguma "em seus próprios termos", conforme insistem alguns materialistas da Filosofia da Mente, quando afirmam que emoções, pensamentos, crenças, desejos, etc. nada mais

18 Sobre os argumentos para a afirmação da irredutibilidade dos qualia, conferir: Nagel, T. "What Is It Like to Be a Bat?" In: Hofstadter, D. R. \& Dennett, D. C. (orgs.) The Mind'S I. Fantasies and Reflections on Self and Soul. Penguin Books, ([1974] 1981), pp. 391-392; Jackson, F. "What Mary Didn't Know". In: Rosenthal, D. M. (org.): The Nature of Mind. Oxford University Press, ([1986]1991), p. 392.

19 Cf. Fernandes, S. L. de C. Filosofia e Consciência. Uma investigação ontológica da Consciência. Rio de Janeiro: Areté Editora, 1995, p. 256

20 Sobre o materialismo redutivo de tais autores, conferir: Place, U. T. "Is Consciousness a Brain Process?". In: Beakley, B. \& Ludlow, P. (orgs.) The Phylosophy of Mind: Classical Problems/ Contemporary Issues, p. 34; Smart, J. J. C. "Sensations and Brain Processes". In: Rosenthal, D. M. (org.) The Nature of Mind, pp. 169-176; Churchland, P. M. Matter and Consciousness. A Contemporary Introduction to the Philosophy of Mind. Cambridge, Mass.: MIT Press, 1984, p. 30. 
são que conexões sinápticas, descargas eletroquímicas, etc. Neste sentido, as considerações críticas de Sérgio Fernandes apontam tanto para a retomada do problema da "autorreferência", no qual incorrem os autores que afirmam a irredutibilidade do caráter qualitativo da experiência consciente, quanto para os excessos de um reducionismo ontológico, inaceitável em ciência, no qual incorrem os materialistas citados.

Mas, se Sérgio Fernandes encontra-se entre os entusiastas de uma "ciência da mente", diverge, drasticamente, daqueles que aspiram a uma "ciência da consciência". Em Filosofia e Consciência, o autor afirma-nos que a intencionalidade seria uma "propriedade extrínseca" da mente, mantendo-se coerente com a sua teoria das qualidades. Tomar a intencionalidade em termos "extrinsicalistas" é tomá-la como uma propriedade passível de definição operacional, por intermédio da qual identificamos e classificamos determinados comportamentos como "intencionais". Para o autor, tal propriedade poderia ser, inclusive, "executada" por outro sistema (um computador, por exemplo) que não o cérebro humano, supostamente programado para realizar as funções requeridas pela referida definição. No entanto, contrariando toda uma geração de filósofos contemporâneos (na qual se inserem Brentano, Husserl, Searle, dentre outros), não hesita em dizer que a "intencionalidade" é uma propriedade da mente e não propriamente da consciência. Para Sérgio Fernandes, o que comumente chamamos de "consciência intencional" não é senão uma "forma de inconsciência" da mente $e^{21}$. Mas, se a dita "consciência intencional" é uma "forma de inconsciência", o que definiria, propriamente, a consciência para o autor?

Ao se referir à "consciência", Sérgio Fernandes chama-nos a atenção para algo que, até certo ponto, surpreende o leitor habituado com os debates na Filosofia da Mente. Trata-se de destacar não a intencionalidade, mas o "caráter diáfano" da experiência consciente. Nos termos do autor, pensar a consciência em termos de diafaneidade consiste, em sentido metafórico, em tomá-la como uma "janela absolutamente transparente" por intermédio da qual percebemos a paisagem do mundo que, por sua vez, aparece-nos como algo "opaco". Persistindo em sua transparência, a consciência contrapõe-se a tudo aquilo que dispõe de algum nível de opacidade. Daí o autor nos dizer:

21 Cf. Fernandes, S. L. de C. Filosofia e Consciência. Uma investigação ontológica da Consciência. Rio de Janeiro: Areté Editora, 1995, p. 108. 
"A consciência - eis um lugar comum - não aparece"22. Sérgio Fernandes concebe a consciência como "diafaneidade", através da introdução do que ele mesmo denomina, em Filosofia e Consciência, de "Mito do Jogo de Luz". A primeira condição deste "Jogo" é, nos diz ele: "Luz difusa, sem fonte discernível"23. Tratar-se-á de compreender a "estrutura" deste jogo. O professor começa o seu mito, afirmando-nos que: "Uma vidraça totalmente limpa, completamente transparente, nesse oceano infinito de luz não se distinguiria dele. Se houvesse atrás dela alguém para ver, não a veria" 24 . Se experimentássemos olhar, ora para o que vemos através da janela, ora para a vidraça perfeitamente limpa, não notaríamos distinção alguma, exceto se houvesse algum resíduo (uma "sujeira" qualquer) que tornasse a vidraça "opaca". Mas, a própria estrutura do mito revela que tal possibilidade seria uma ilusão, pois "ainda que a vidraça esteja suja, só nos damos conta de que ela está suja porque entre ela e nós há uma 'outra' vidraça perfeitamente limpa"25.

O autor esclarece-nos que não é a consciência que "aparece" quando sabemos que temos consciência obscura de algo. Em outros termos, não é a consciência que se obscurece. Por mais escura que seja tal obscuridade, ou bem temos consciência dela, ou bem não a temos, nos diz o autor. Sérgio Fernandes convida, então, o leitor para um "experimento mental", à moda dos autores da Filosofia da Mente: pede-nos que imaginemos uma situação na qual estamos em vias de desmaiar. Acrescenta que, em tais situações, não é, propriamente, a consciência aquilo que perdemos, pois, até que pudéssemos "perdê-la", até que, digamos, ela "desaparecesse" (na verdade, segundo ele, só poderia parecer desaparecer), tínhamos consciência - não menos clara - de que estávamos a "perdê-la". Para o autor, não é, propriamente, a consciência o que perdemos neste tal "jogo de obscurecimento". A consciência - como uma "vidraça" perfeitamente límpida - persiste em sua transparência, de modo que, quando procuramos a consciência, encontramos tudo o que "aparece" que, por sua vez, se obscurece ou clareia. No experimento mental em questão, o que se contrapõe como opacidade à consciência é, propriamente, o "eu". Neste ponto da movimentação simbólica do "Jogo de Luz", Sérgio

22 Cf. Fernandes, S. L. de C. Filosofia e Consciência. Uma investigação ontológica da Consciência. Rio de Janeiro: Areté Editora, 1995, p. 151.

23 Cf. Ibidem, p. 149.

24 Cf. Ibidem, p. 151.

25 Cf. Idem. 
Fernandes esclarece-nos que: no lugar da "luz difusa", passamos a ter uma "janela transparente" (uma luz que "transparece"). Embora não se distinga da luz, a "translucidez" da vidraça restringe o que antes era tão somente uma luz difusa. Deu-se, então, em tal movimentação, a substituição do que era "indeterminado" por uma "determinação". O autor pergunta-nos, em seguida: o que resta para além desta substituição da "luz difusa" pela "vidraça diáfana"? Resta o que não é transparência e, portanto, na visão do autor, o que não é consciência. Resta, em outros termos, a "inconsciência" que, por sua vez, equivale à "opacidade". Neste sentido, o professor Sérgio afirma-nos que a inconsciência pode ser um estado da mente, mas jamais da consciência, pois, ao "perder" o que o leitor julgava, no experimento mental em questão, ser a sua consciência, esta como que se deslocava enquanto "vidraça transparente", de modo que o que lhe aparecia era um "eu", a ponto de desmaiar, perder-se, apagar-se, etc. Para Sérgio Fernandes, é justamente porque pensávamos erroneamente que esta consciência era "consciência de algo", ou seja, que estávamos a perdê-la, ou que ela estava a "obscurecer-se", que não podíamos compreender a sua verdadeira natureza imutável e absolutamente translúcida.

Contrariando a grande maioria dos autores da Filosofia da Mente contemporânea, para os quais a consciência encontra-se em "relação intencional" com seus conteúdos ou objetos, Sérgio Fernandes é categórico em afirmar que o que chamamos de "consciência intencional" é, propriamente, uma "forma de inconsciência". Neste sentido, o autor nos diz: "A consciência intencional não é consciente, no verdadeiro sentido do termo consciente" ${ }^{\text {"26 }}$, pois, o que chamamos de "intencionalidade" não pode ser um "estado de consciência". Caso fosse um "estado", haveria outros "estados", de modo que o estado da consciência poderia "alterar-se". Mas, conforme o "Mito do Jogo de Luz", a consciência persiste, inalteravelmente, em sua transparência, de maneira que não poderíamos falar em um estado "seu" (tampouco em suas variações). Relacionar-se intencionalmente com objetos pode ser, segundo o autor, um estado da mente, jamais da consciência. Como nos diz o professor Sérgio, ao retomar o experimento mental do desmaio: "O que me acontece quando eu tenho 'consciência' de que vou perder a consciência não pode ser consciência, pois se esta é imperdível, não pode ser consciência de perder-se a si mesma"27. Portanto, para Sérgio Fernandes, se o que nós temos quando temos "consciência" de

26 Cf. Fernandes, S. L. de C. Filosofia e Consciência. Uma investigação ontológica da Consciência. Rio de Janeiro: Areté Editora, 1995, p. 156.

27 Idem. 
que vamos perdê-la não é consciência, então é uma forma de inconsciência que, comumente, chamamos de "consciência intencional". Trata-se, antes, de um estado mental que se expressa, segundo o autor, pelo juízo falso: "Vou perder a consciência", tendo como objeto do estado mental "a perda da minha consciência". Para Sérgio Fernandes, o juízo corrigido seria: "Aquilo (o objeto) vai desmaiar, dormir, cair morto, etc', 'Vou perder-me a mim mesmo', ou "Vou perder meu senso (exclusivo) de eu'"28. É, portanto, esse "eu" que vai, digamos, "mudar de estado", não a consciência.

O "Jogo de Luz" de Sérgio Fernandes mostra-nos, por fim, o "eu" como uma "opacidade" que, por sua vez, equivale à inconsciência (em sentido meramente negativo, de "ausência de consciência"). Mas, o mesmo Jogo nos diz que a consciência não pode se ausentar, pois ela persiste em sua transparência. Tal inconsciência é, portanto, no referido sentido, uma "ilusão" (o autor chega a dizer que tal ilusão deve ser um "efeito de luz", já que o jogo é de luz ${ }^{29}$. Afinal, no início do Jogo de Luz, somente havia "luz difusa", nada mais. Lá, na translucidez, adverte-nos o autor, não havia "ninguém”. Mas, se a consciência é imutavelmente translúcida, o Jogo não poderia deter-se na transparência? Para Sérgio Fernandes, não! Afinal, a estrutura do Mito do Jogo de Luz convida-nos à compreensão da consciência, abrindo-nos uma dualidade que coloca, de um lado, a "transparência" (diafaneidade) e, de outro, o seu oposto, a "opacidade". Tal compreensão torna-se, para o ilustre professor, uma tarefa propriamente "filosófica", cuja realização permite-nos avançar em uma investigação ontológica da consciência.

\section{Referências}

BERGSON, H. Essai sur les données immédiates de la conscience. In: Oeuvres. Édition du Centenaire. Paris: Presses Universitaires de France, ([1889] 1959).

"Introduction à la Métaphysique". La Pensée et le Mouvant. In: Oeuvres.

Édition du Centenaire. Paris: Presses Universitaires de France, ([1903] 1959).

"La Conscience et la Vie". L'Énergie Spirituelle. In: Oeuvres. Édition du

Centenaire. Paris: Presses Universitaires de France, ([1911] 1959).

CHURCHLAND, P. M. Matter and Consciousness. A Contemporary Introduction to the Philosophy of Mind. Cambridge, Mass.: MIT Press, 1984.

28 Cf. Idem.

29 Cf. Ibidem, p. 158. 
DESCARTES, R. Les Méditations Métaphysiques. Commentaire de J-L Poirier. Paris: Bordas, 1987.

FERNANDES, S. L de C. Filosofia e Consciência. Uma investigação ontológica da Consciência. Rio de Janeiro: Areté Editora, 1995.

"Qualidade e Quantidade em pesquisa psicológica". In: Fernandes, S. L. de C. \& Castanheira, M. (orgs.) Psicologia e Mente Social. Construção de teoria e problemas metodológicos. Rio de Janeiro: Editora Central da UGF, 1996. pp. 201-251.

HUME, D. A Treatise of Human Nature. Volume 1. A Critical Edition. Edited by David Fate Norton and Mary J. Norton. Oxford, New York: Clarendon Press, 2007.

JACKSON, F. "What Mary Didn't Know". In: Rosenthal, D. M. (org.): The Nature of Mind. Oxford University Press, ([1986]1991), pp. 392-394.

LOCKE, J. An Essay Concerning Human Understanding. Complete and Unabridged. Collated and annotated by Alexander Campbell Fraser (In two Volumes). New York: Dover Publications, INC, ([1690]1959).

NAGEL, T. "What Is It Like to Be a Bat?" In: Hofstadter, D. R. \& Dennett, D. C. (orgs.) The Mind'S I. Fantasies and Reflections on Self and Soul. Penguin Books, ([1974] 1981), Chapter 24, pp. 391-403.

PLACE, U. T. "Is Consciousness a Brain Process?" In: Beakley, B. \& Ludlow, P. (orgs.). The Phylosophy of Mind: Classical Problems/ Contemporary Issues. Cambridge, Mass.: MIT Press, ([1956]1992), pp. 33-40.

SMART, J. J. C. "Sensations and Brain Processes". In: Rosenthal, D. M. (org.). The Nature of Mind. Oxford University Press, ([1959]1991), pp. 169-176. 